\title{
BACTEREMIA DURING CANAL WALL UP MASTOIDECTOMY IN CASES OF CHOLESTEATOMA
}

\author{
By

\section{Hashem Mohamed Hashem, Atef El-Maraghy, Mohamed El-Sharkawy and Ahmed Abd El-Moez Ali}

Department of Otorhinolaryngology, Faculty of Medicine, Al-Azhar University

E-mail: drhashemmohamed1990@gmail.com

\begin{abstract}
Background: Otitis media refers to a group of complex infectious and inflammatory diseases affecting the middle ear. Bacteremia is the presence of viable bacteria in the circulating blood. It has been reported that it is associated with some surgical procedures.

Objective: To investigate the risk of bacteremia development during surgery in patients who underwent mastoidectomy for chronic otitis media.

Patients and Methods: This was a prospective study carried out at Hearing and Speech Institute, Egypt during the period between March and December 2019. The study included 30 patients with chronic otitis media (17 males and 13 females) who were scheduled for mastoidectomy. Preoperative routine ENT examination and microscopic examination were done. Blood samples were taken before and after the operation for the evaluation of microorganisms. Smear cultures were obtained, and the growing microorganisms were identified with the traditional method.

Results: Cholesteatoma was the major complaint among all patients, 27 cases $(90.0 \%)$ complained of intermittent ear discharge, 16 cases (53.3\%) complained of hearing loss and only 3 cases (10.0\%) complained of tinnitus. The results showed that 19 cases $(63.3 \%)$ developed bacteremia postoperatively. Streptococcus spp was the main organism found in 6 cases $(20.0 \%)$ in preoperative external ear canal and in 7 cases $(23.3 \%)$ in postoperative dressing smear cultures, followed by Pseudomonas aeruginosa in 5 cases $(16.7 \%)$ and 4 cases (13.3\%), Diphteroid bacilli in 4 cases $(13.3 \%)$ and 2 cases $(6.7 \%)$, Coagulase staphylococcus in 4 cases (13.3\%) and 2 cases (6.7\%), also, Klebsiella spp was found in 2 cases (6.7\%) and 2 cases (6.7\%) for preoperative external ear canal and postoperative dressing smear cultures, respectively. Regarding type and number of bacteria growing in blood culture immediately after surgery, the results showed that Streptococcus spp was presented in 11 cases (58.0\%). Both Coagulase (-) staphylococcus and Bacillus spp with spores were found in 4 cases $(21.0 \%)$.
\end{abstract}

Conclusion: The risk of bacteremia should be considered in the preoperative period for the patients undergoing mastoidectomy. Postoperative use of antibiotics prevents several undesired complications and increases the success rate of the surgical procedure.

Keywords: Bacteremia, mastoidectomy and cholesteatoma.

\section{INTRODUCTION}

Otitis media $(\mathrm{OM})$ refers to a group of complex infectious and inflammatory diseases affecting the middle ear. OM in general is very common as some studies show that around $80 \%$ of children should have experienced at least one episode by their third birthday (Dickson, 2014). OM has been broadly classified into two main types, i.e. acute and chronic. Chronic otitis 


\section{HASHEM MOHAMED HASHEM et al.,}

media (COM) continues to be an important health problem across the world as it has been since the beginning of humanity. The disease is defined as the perforation of and the discharge from the tympanic membrane together with the infection of the middle ear and the mastoid bone (Mittal et al., 2015). Chronic otitis media is often associated with fussiness, otalgia, and fever, but these signs and symptoms are nonspecific and are associated with other childhood infections (Yawman et al., 2010). In surgical treatment of COM, it is not possible to eliminate cholesteatoma and infections by preserving normal anatomic structures and to regain hearing function in each and every patient (Allen et al., 2014). Although restoration of the hearing loss and the preservation of anatomy are important aspects, eradication of the disease should be the main principle in the surgical procedures (Luers and Hüttenbrink, 2016).

Bacteriemia is the presence of viable bacteria in the circulating blood, the clinical picture caused by the spread of the bacteria to the circulation characterized by fever and chills (Dagasso et al., 2018). Bacteremia can have several important health consequences. The immune response to the bacteria can cause sepsis and septic shock, which has a high mortality rate (Munro et al., 2018). Although its incidence depends on the type of performed surgery, bacteriemia is one of the most important complications of the postoperative period (Dagasso et al., 2018).

The objective of this study was to investigate the risk of bacteriemia development during surgery in patients who underwent mastoidectomy for chronic otitis media.

\section{PATIENTS AND METHODS}

This was a prospective study that carried out at Hearing and Speech Institute, Egypt during the period between March and December 2019 after the approval of the Ethical committee. The study included 30 patients with chronic otitis media (17 males and 13 females) who were scheduled for mastoidectomy. Patients had not received any antibiotics for at least 1 month before surgery.

After preoperative routine ENT examination, a microscopic examination was performed in an attempt to identify any discharge, perforation, polyps, cholesteatoma, granulation tissue, and changes in middle ear mucosa. Preoperatively, outer ear canal smear cultures were taken from all patients. General anesthesia was used for operating all included patients. Antiseptic or antimicrobial solution was used for washing the outer ear canal and tympanic cavity. A spongel tampon was placed to the mastoid and or tympanic cavities of the patients who underwent to modified radical mastoidectomy at the end of the surgery.

A volume of $10 \mathrm{ml}$ of blood was drawn from all patients immediately before, and after the surgery. The blood samples were separated into two equal parts, and were transferred into liquid media prepared for aerobic and anerobic microorganisms, and were evaluated with BacT/Alert (Organon Tekniko Corp NC 27704) automated blood culture system.

Smear cultures were obtained with a cotton tip while retrieving the dressing. 
All the obtained culture samples were sent to the microbiology laboratory within 30 minutes. Smear samples were grown on bloody agar and EMG agar media and incubated at $37{ }^{\circ} \mathrm{C}$ for 16 to 24 hours. The growing microorganisms were identified with traditional methods "at the end of the incubation period". The outer ear canal smear cultures obtained before the surgery, and the pressure dressing smear cultures were compared for the similarity of the microorganisms that they contained, and it was analyzed whether these microorganisms carried the risk for bacteremia caused by the operation.

\section{Statistical analysis:}

Statistical analysis was carried out using SPSS program (version 20). Mean and standard deviation (SD) were calculated for continuous variables and number \& $(\%)$ were used for categorical variables.

\section{RESULTS}

This study included 30 patients (17 males "56.7\%" and 13 females "43.3\%"). The mean age of them was $24.9 \pm 9.1$ ranged (16-52). Regarding the major complaints of COM of studied patients, Cholesteatoma was the major complaint.
Of the 30 included patients, 27 cases (90.0\%) complained of intermittent ear discharge, 16 cases $(53.3 \%)$ complained about hearing loss and only 3 cases $(10.0 \%)$ complained of tinnitus (Table 1).

Table (1): Demographic variables and complains of studied group

\begin{tabular}{|c|c|c|}
\hline \multicolumn{2}{|c|}{ Variables } & $\begin{array}{c}\text { Descriptive } \\
(\mathbf{n = 3 0 )}\end{array}$ \\
\hline \multirow{2}{*}{ Sex } & Age (year) & $29.4 \pm 9.1(16-52)$ \\
\cline { 2 - 3 } & Male & $17(56.7 \%)$ \\
\hline \multirow{3}{*}{ Complaints } & Female & $13(43.3 \%)$ \\
\cline { 2 - 3 } & intermittent ear discharge & $27(90.0 \%)$ \\
\cline { 2 - 3 } & hearing loss & $16(53.3 \%)$ \\
\hline
\end{tabular}

Regarding the microorganisms isolated from preoperative external ear canal and postoperative dressing smear cultures. Streptococcus spp was the main organism found in 6 cases $(20.0 \%)$ in preoperative external ear canal and in 7 cases $(23.3 \%)$ in postoperative dressing smear cultures, followed by Pseudomonas aeruginosa in 5 cases $(16.7 \%)$ and 4 cases $(13.3 \%)$,
Diphteroid bacilli in 4 cases $(13.3 \%)$ and 2 cases $(6.7 \%)$, Coagulase staphylococcus in 4 cases $(13.3 \%)$ and 2 cases $(6.7 \%)$, also, Klebsiella spp was found in 2 cases $(6.7 \%)$ and 2 cases $(6.7 \%)$ for preoperative external ear canal and postoperative dressing smear cultures, respectively (Table $\mathbf{2}$ ). 
Table (2): Microorganisms isolated from preoperative external ear canal and postoperative dressing smear cultures

\begin{tabular}{|l|c|c|}
\hline Microorganisms & $\begin{array}{c}\text { Microorganisms growing } \\
\text { in preoperative external } \\
\text { ear canal } \mathrm{n}(\%)\end{array}$ & $\begin{array}{c}\text { Microorganisms growing } \\
\text { in postoperative dressing } \\
\text { smear cultures n (\%) }\end{array}$ \\
\hline Streptococcus spp & $6(20.0 \%)$ & $7(23.3 \%)$ \\
\hline $\begin{array}{l}\text { Pseudomonas } \\
\text { aeruginosa }\end{array}$ & $5(16.7 \%)$ & $4(13.3 \%)$ \\
\hline Diphteroid bacilli & $4(13.3 \%)$ & $2(6.7 \%)$ \\
\hline $\begin{array}{l}\text { Coagulase (-) } \\
\text { staphylococcus }\end{array}$ & $4(13.3 \%)$ & $2(6.7 \%)$ \\
\hline $\begin{array}{l}\text { Coagulase (+) } \\
\text { staphylococcus }\end{array}$ & $3(10.0 \%)$ & $2(6.7 \%)$ \\
\hline Klebsiella spp & $2(6.7 \%)$ & $2(6.7 \%)$ \\
\hline Haemophilus spp & $2(6.7 \%)$ & - \\
\hline Neisseria spp & $2(6.7 \%)$ & $1(3.0 \%)$ \\
\hline Candida spp & $1(3.0 \%)$ & - \\
\hline Acinobacter spp & $1(3.0 \%)$ & - \\
\hline Gram (-) basil & $1(3.0 \%)$ & $1(3.0 \%)$ \\
\hline
\end{tabular}

The results showed that 19 cases $(63.3 \%)$ developed bacteremia postoperatively (fig. 1).

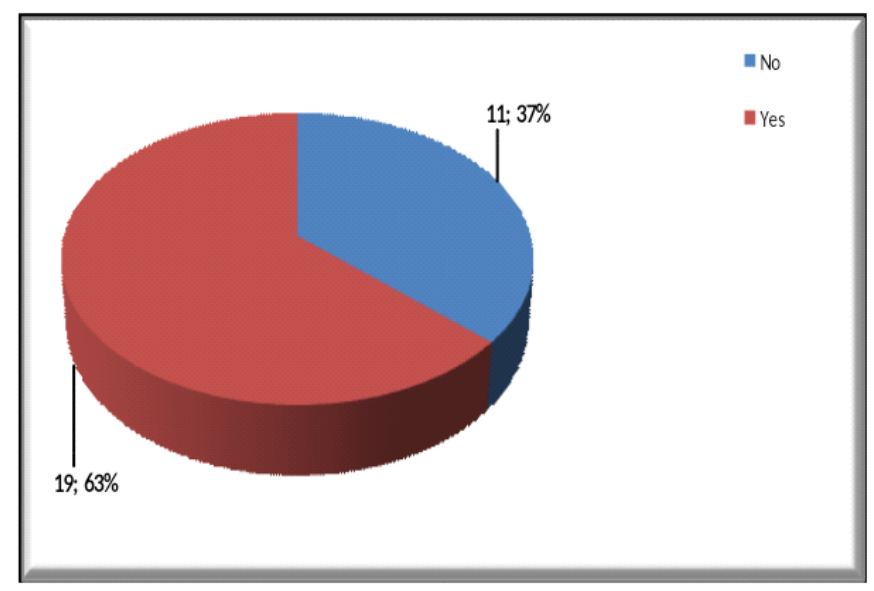

Figure (1): Cases developed bacteremia postoperatively

Regarding type and number of bacteria growing in blood culture immediately after surgery, the results showed that Streptococcus spp was presented in 11 cases (58.0\%) and both Coagulase (-) staphylococcus and Bacillus spp with spores were found in 4 cases $(21.0 \%)$ (fig. 2). 


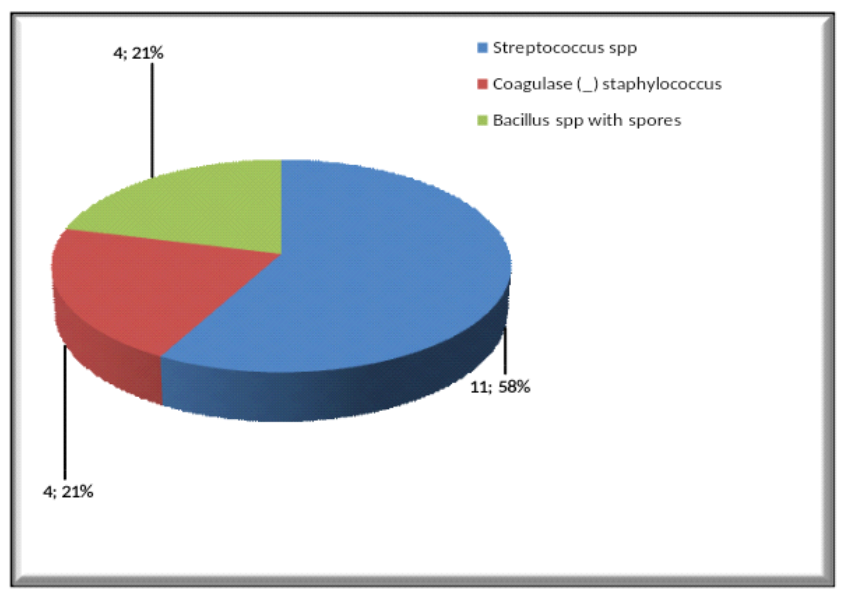

Figure (2): Distribution of the microorganisms growing in postoperative blood cultures.

\section{DISCUSSION}

In the current study, Streptococcus spp was the main organism found in $20.0 \%$ in preoperative external ear canal, and in $23.3 \%$ in postoperative dressing smear cultures, followed by Pseudomonas aeruginosa in $16.7 \%$ and $13.3 \%$. Diphteroid bacilli in $13.3 \%$ and $6.7 \%$. Coagulase staphylococcus in $13.3 \%$ and $6.7 \%$ also. Klebsiella spp was found in $6.7 \%$ and $6.7 \%$ for preoperative external ear canal and postoperative dressing smear cultures, respectively. In chronic otitis media without cholesteatoma, the most common isolated microorganisms are Pseudomonas aeruginosa and staphylococci species, mainly S. aureus (Yawman et al., 2010). Also Gramnegative organisms are isolated, such as Klebsiella, Proteus or Haemophilus and gram-positive bacteria, with predominance of Streptococci. In the periods of otorrhea the isolates are mostly polymicrobial. The isolated microorganisms are the same in otitis media with cholesteatoma and simple chronic otitis media.
The main finding of the current study revealed that $63.3 \%$ developed bateremia postoperatively. So, the incidence of bateremia in our study was higher than in previous studies. Uysal et al., (2014) investigated the relationship between the amount of bleeding and bacteremia during tympanomastoidectomy surgery. They found that blood cultures taken preoperatively were negative. However, the cultures obtained intraoperative were positive in $12.3 \%$ who underwent tympanomastoidectomy, and bacteremia was more frequent among those with a greater amount of bleeding during the surgery. Also, Shishegar and Ashraf (2014) studied post-tonsillectomy bacteremia in children. They found that $76.1 \%$ and $79.6 \%$ cultures from surface and depth of tonsils represented multiple microorganisms, respectively. Besides, staphylococci coagulase positive was the most common organism in both surface and depth of tonsils.

It has been reported that if the bacteria can reach the circulation through mucosal capillaries during upper and lower gastrointestinal system endoscopies, 
nasotracheal intubations, tonsillectomies, dental and urological surgical procedures. It can also pass into the blood stream via similar routes during traumas such as nasal mucosal incision, nasal tamponade, septoplasty and septorhinoplasty.

In the present study, regarding type and number of bacteria growing in blood culture immediately after surgery, the results showed that Streptococcus spp was presented in $58.0 \%$ and both Coagulase (-) staphylococcus and Bacillus spp with spores were found in $21.0 \%$. Uysal et al. (2014) investigated the relationship between the amount of bleeding and bacteremia during tympanomastoidectomy surgery. Shishegar and Ashraf (2014) found that staphylococci coagulase positive was the most common organism in both surface and depth of tonsils. Peptostreptococcus are anaerobic grampositive cocci that are normally found in the flora of the mouth and colon (Levinson, 2012). Even though it is rare, Peptostreptococcus is associated with IE and is also known for its high morbidity (Minces et al., 2010). Another pathogen found in the blood samples was the Streptococcus anginosus, also found primarily in the mouth and colon (Levinson, 2012).

\section{CONCLUSION}

The risk of bacteremia should be considered in the preoperative period for the patients undergoing mastoidectomy. Bacteremia may lead to serious complications in patients with particular risk factors such as cardiovascular or valvular diseases. Postoperative use of antibiotics is recommended especially in patients with ear cholesteatoma who present specific risk factors which prevents several undesired complications and increases the success rate of the surgical procedure.

\section{Source of funding: None.}

Conflict of interest: There are no conflicts of interest.

\section{REFERENCES}

\section{Allen E.K., Manichaikul A., Chen} W.M., Rich S.S., Daly K.A. and Sale M. (2014): Evaluation of replication of variants associated with genetic risk of otitis media. PLoS ONE, 9: e104212.

2. Dagasso G., Conley J., Parfitt E., Pasquill K., Steele L. and Laupland K. (2018): Risk factors associated with bloodstream infections in end-stage renal disease patients: a populationbased study. Infect Dis (Lond), 50(1112):831-836.

3. Dickson G. (2014): Acute otitis media. Prim Care, 41:11-18.

4. Koc S., Gürbüzler L., YeniÅŸehirli G., Eyibilen A, Alada $\ddot{A} \ddot{Y}$ I. and Corcoran K.J. (2011): The comparison of bacteremia and amount of bleeding during adenotonsillectomy. Int J Pediatr. Otorhinolaryngol., 75: 1214.

5. Levinson W. (2012): Review of Medical Microbiology \&amp; Immunology, 12e. Chapter 27. Minor Bacterial Pathogens. 12th ed. New York, NY: McGraw-Hill, 950-1079.

6. Luers J.C. and Huittenbrink B. (2016): Surgical anatomy and pathology of the middle ear. J Anat., 228(2): 338-353.

7. Minces L.R., Shields R.K., Sheridan K., Ho K.S. and Silveira F.P. (2010): 
Peptostreptococcus infective endocarditis and bacteremia. Analysis of cases at a tertiary medical center and review of the literature. Anaerobe, 16(4):327-330.

8. Mittal R., Christopher V. and Gerring R. (2015): Current concepts in the pathogenesis and treatment of chronic suppurative otitis media. J Med Microbiol., 64(Pt 10): 1103-1116.

9. Munro A.P.S., Blyth C.C., Campbell A.J. and Bowen A.C. (2018): Infection characteristics and treatment of Staphylococcus aureus bacteraemia at a tertiary children's hospital. BMC Infect. Dis., 18(1):387.

10. Shishegar M. and Ashraf M.J. (2014): Posttonsillectomy Bacteremia and Comparison of Tonsillar Surface and Deep Culture. Advances in Preventive Medicine, Article ID 161878, 5 pages

11. Uysal E.B., Polat K., Onder U.I. and Koç S. (2014): The Comparison of Bacteremia and Amount of Bleeding During Tympanomastoidectomy. Otolaryngology, 4: 153-172.

12. Yawman D., Mahar P., Blumkin A., and Conners G. (2010): Evaluating Children with Otitis Media for Bacteremia or Urinary Tract Infection. International Journal of Pediatrics. Article ID 790167, 5 pages. 


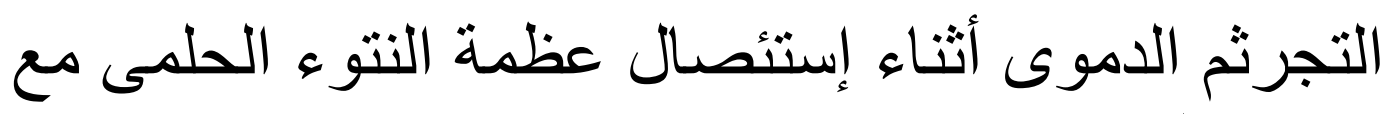

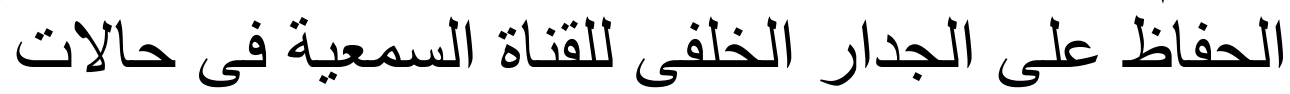

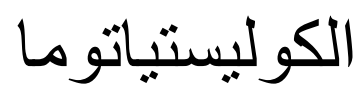

هاثم محمد هاثم، عاطف المراغى، محمد الثرقاوى، أحمد عبد المعز على قسم الأنف والأذن والحنجرة، كلية طب الأزهر

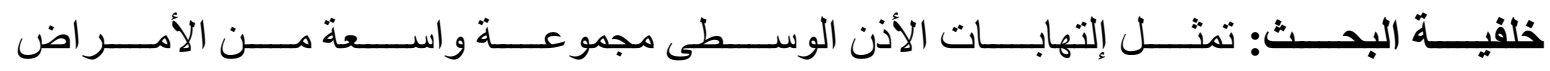

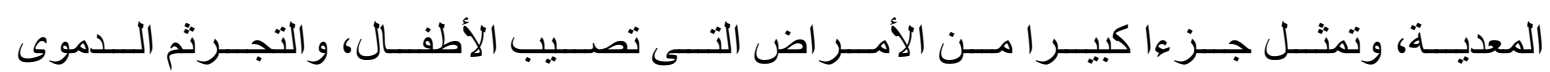
هو وجود بكتيريا مختلفة فى تيار الدم أثناء إجر اء بعض التهر التداخلات الجراحية.

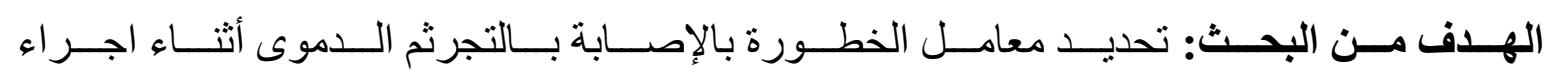

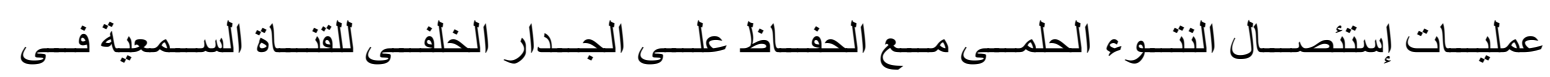
حالات إلتهابات الأذن الوسطى المزمنة.

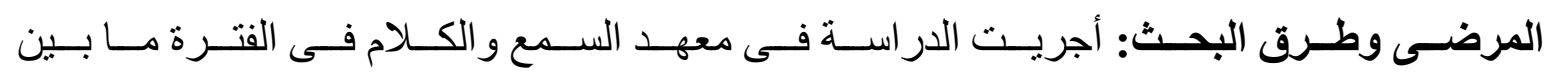

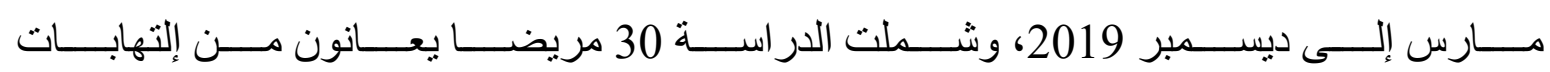

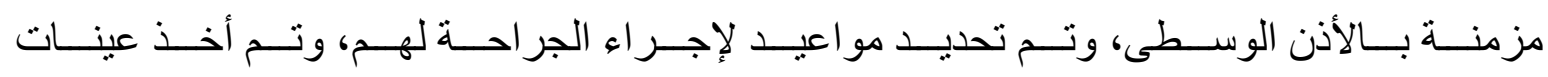

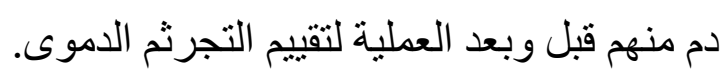

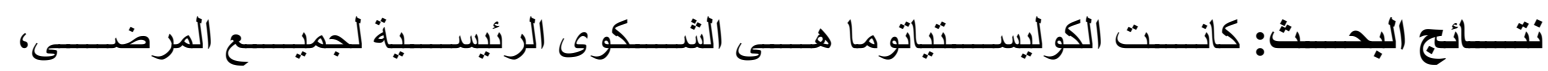

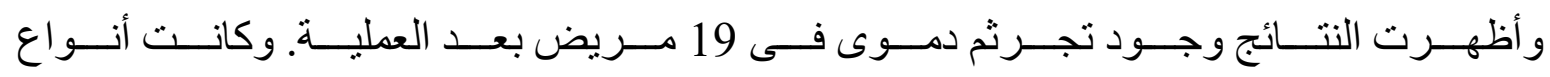
البكتريا السبحية هى الأنواع الرئيسية فى الإصدابة.

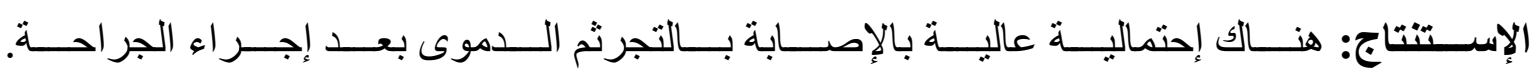

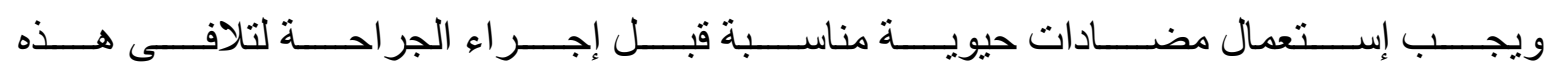
المضاعفات. 